Вісник Харківського національного університету імені В.Н. Каразіна Серія "Математика, прикладна математика і механіка" Tом 87,2018 , c. $4-12$

УДК 517.5
Visnyk of V.N.Karazin Kharkiv National University Ser. "Mathematics, Applied Mathematics and Mechanics"

Vol. 87, 2018, p. 4-12

DOI: $10.26565 / 2221-5646-2018-87-01$

\title{
Approximation of classes of Poisson integrals by Fejer sums
}

\author{
O.O. Novikov ${ }^{1}$, O.G. Rovenska ${ }^{2}$, Yu.A. Kozachenko ${ }^{1}$ \\ ${ }^{1}$ Donbass State Pedagogical University, Slov'yansk, 19 G. Batuka, 84116, Ukraine \\ ${ }^{2}$ Donbass State Engineering Academy, Kramatorsk, 72 Akademicheskaya, \\ 84313, Ukraine \\ sgpi.slav@dn.ua,rovenskaya.olga.math@gmail.com,sgpi.slav@dn.ua
}

For upper bounds of the deviations of Fejer sums taken over classes of periodic functions that admit analytic extensions to a fixed strip of the complex plane, we obtain asymptotic equalities. In certain cases, these equalities give a solution of the corresponding Kolmogorov-Nikolsky problem.

Keywords: asymptotic equality; Poisson integrals; Fejer sums

Новіков О.О., Ровенська О.Г., Козаченко Ю.А. Наближення класів інтегралів Пуассона сумами Фейєра. Розширено проміжок параметра, що визначає клас функцій, для якого були справедливими знайдені до цього асимптотичні рівності для верхніх граней відхилень сум Фейєра на класах періодичних функцій, що дозволяють аналітичне подовження у фіксовану смугу комплексної площини. В деяких випадках ці рівності забезпечують розв'язок відповідної задачі Колмогорова-Нікольського.

Ключові слова: асимптотична рівність; інтеграли Пуассона; суми Фейєра

Новиков О.А., Ровенская О.Г., Козаченко Ю.А. Приближение классов интегралов Пуассона суммами Фейера. Расширен промежуток параметра, определяющего класс функций, для которых были справедливы найденные ранее асимптотические равенства для верхних граней уклонений сумм Фейера на классах периодических функций, допускающих аналитическое продолжение в фиксированную полосу комплексной плоскости. В определенных случаях эти равенства обеспечивают решение соответствующей задачи Колмогорова-Никольского.

Ключевые слова: асимптотическое равенство; интегралы Пуассона; суммы Фейера

2010 Mathematics Subject Classification: 42A10.

\section{Introduction}

Let $C_{\beta, \infty}^{q}$ (see, e.g., [1]) be classes of continuous $2 \pi$-periodic functions given by the convolutions

$$
f(x)=A_{0}+\frac{1}{\pi} \int_{-\pi}^{\pi} f_{\beta}^{q}(x+t) P_{\beta}^{q}(t) d t,
$$

(c) O. O. Novikov, O. G. Rovenska, Yu. A. Kozachenko, 2018 
where

$$
P_{\beta}^{q}(t)=\sum_{k=1}^{\infty} q^{k} \cos \left(k t+\frac{\beta \pi}{2}\right), \quad q \in(0 ; 1), \quad \beta \in \mathbb{R},
$$

is the well-known Poisson kernel, the function $f_{\beta}^{q}(x)$ either satisfies the condition

$$
\text { ess } \sup _{x \in[-\pi ; \pi]}\left|f_{\beta}^{q}(x)\right| \leq 1 .
$$

In this case, the sets $C_{\beta, \infty}^{q}$ consist of $2 \pi$-periodic functions that admit extension to functions $f(z)=f(x+i y)$ analytic in the strip $|y|<\ln \left(\frac{1}{q}\right)$ (see, e.g., [1]); these functions are called the Poisson integrals.

Further, let $f(x)$ be a $2 \pi$-periodic summable function $(f \in L)$, let

$$
S[f]=\frac{a_{0}}{2}+\sum_{k=1}^{\infty}\left(a_{k} \cos k x+b_{k} \sin k x\right)
$$

be its Fourier series, and let $a_{k}=a_{k}(f)$ and $b_{k}=b_{k}(f), k=0,1, \ldots$, be its Fourier coefficients.

Denote by $\Lambda=\left\|\lambda_{k}^{(n)}\right\|, k, n=0,1, \ldots$ an arbitrary triangular matrix of numbers by using which we associate every function $f \in L$ with a sequence of trigonometric polynomials $U_{n}(f ; x ; \Lambda)$ of the form

$$
U_{n}(f ; x ; \Lambda)=\frac{a_{0}}{2}+\sum_{k=1}^{n-1} \lambda_{k}^{(n)}\left(a_{k} \cos k x+b_{k} \sin k x\right) .
$$

Thus, any triangular matrix $\Lambda$ gives a method for the construction of polynomials $U_{n}(f ; x ; \Lambda)$ or, in other words, specific sequence of polynomial operators $U_{n}(f ; \Lambda)$ defined on the set $L$. In this case, one also says that the matrix $\Lambda$ defines a specific method ( $\Lambda$-method) for summing Fourier series. It is clear that the operators $U_{n}(f ; \Lambda)$ are linear. For this reason, $\Lambda$-methods are called linear summation methods for Fourier series.

For arbitrary natural $p<n$ the polynomials that are given by relationship

$$
\lambda_{k}^{(n)}= \begin{cases}1 & 1 \leq k \leq n-p \\ 1-\frac{k-n+p}{p} & n-p+1 \leq k \leq n-1\end{cases}
$$

are called de la Vallee Poussin sums. In this case, the polynomials $U_{n}(f ; x ; \Lambda)$ are denoted by $V_{n, p}(f, x)$ and have the form

$$
V_{n, p}(f ; x)=\frac{1}{p} \sum_{k=n-p}^{n-1} S_{k}(f ; x),
$$

where $S_{k}(f ; x), k=0,1, \ldots$ are the partial Fourier sums of order $k$ of the function $f(x)$. If $p=1$, then $V_{n, p}(f ; x)=S_{n-1}(f ; x)$. For $p=n$ sums of this type are called the Fejer sums:

$$
\sigma_{n}(f ; x)=V_{n, n}(f ; x)=\frac{1}{n} \sum_{k=0}^{n-1} S_{k}(f ; x) .
$$


De la Vallee-Poussin sums and their special cases (Fourier sums and Fejer sums) have been extensively studied for many decades by many prominent experts in the theory of functions. In 1946, Nikolsky [2] considered the quantity

$$
\mathcal{E}\left(C_{\beta, \infty}^{q} ; S_{n}\right)=\sup _{f \in C_{\beta, \infty}^{q}}\left\|f(x)-S_{n}(f ; x)\right\|_{C}
$$

where $S_{n}(f ; x)$ is the $n$-th partial sum of the Fourier series of the function $f(x)$, and established the asymptotic equality (as $n \rightarrow \infty)$

$$
\mathcal{E}\left(C_{\beta, \infty}^{q} ; S_{n}\right)=\frac{8 q^{n}}{\pi^{2}} K(q)+O(1) \frac{q^{n}}{n},
$$

where

$$
K(q)=\int_{0}^{\frac{\pi}{2}} \frac{d u}{\sqrt{1-q^{2} \sin ^{2} u}}
$$

is the total elliptic integral of the first kind, $O(1)$ is a quantity uniformly bounded with respect to $n$. In 1980, Stechkin [3] proposed another proof of this result, which allowed to refine the remainder equality

$$
\mathcal{E}\left(C_{\beta, \infty}^{q} ; S_{n}\right)=\frac{8 q^{n}}{\pi^{2}} K(q)+O(1) \frac{q^{n}}{n(1-q)},
$$

where $O(1)$ is a quantity uniformly bounded with respect to $n, q$.

It follows from these equalities that, on the classes of analytic functions, the Fourier sums provide an approximation which coincides in order with the best approximation by the trigonometric polynomials of degree not greater than $n$. However, it is still interesting to make clear how do other approximating aggregates (e.g., de la Vallee-Poussin sums, Fejer sums) behave on the classes mentioned above. These studies may be of interest for computational mathematics and methods of mathematical modeling.

Asymptotic (as $n \rightarrow \infty$ ) equalities for upper bounds of the deviations of de la Vallee Poussin sums for $p$ satisfying $n-p \rightarrow \infty$ on the classes $C_{\beta, \infty}^{q}$ may be found in $[4,5]$ :

$$
\begin{gathered}
\mathcal{E}\left(C_{\beta, \infty}^{q} ; V_{n, p}\right)=\sup _{f \in C_{\beta, \infty}^{q}}\left\|f(x)-V_{n, p}(f ; x)\right\|_{C} \\
=\frac{q^{n-p+1}}{p}\left(\frac{4}{\pi^{2}} K_{q, p}+O(1)\left(\frac{q}{(n-p+1)(1-q)^{s}}\right)\right),
\end{gathered}
$$

where

$$
K_{q, p}=\int_{0}^{\pi} \frac{\sqrt{1-2 q^{p} \cos p t+q^{2 p}}}{1-2 q \cos p t+q^{2}} d t, \quad s=s(p)= \begin{cases}1, & p=1 \\ 3, & p=2,3, \ldots\end{cases}
$$


$O(1)$ is a quantity uniformly bounded with respect to $n, p, q$.

In the case of arbitrary $p=1,2, \ldots, n$ the behavior of the constant $K_{q, p}$ could be inferred by the next identity, proved in [6]:

$$
K_{q, p}=2 \frac{1-q^{2 p}}{1-q^{2}} K\left(q^{p}\right),
$$

where $K(q)$ is the total elliptic integral of the first kind.

Some related problems were studied in $[7,8,9,10,11,12]$.

For $q \in(0 ; 2-\sqrt{3}]$ upper bounds of the deviations of Fejer sums on the classes $C_{0, \infty}^{q}$ were investigated in [13]

$$
\mathcal{E}\left(C_{0, \infty}^{q}, \sigma_{n}\right)=\sup _{f \in C_{0, \infty}^{q}}\left\|f(x)-\sigma_{n}(f ; x)\right\|_{C}=\frac{4 q}{\pi n\left(1+q^{2}\right)}+O(1) \frac{q^{n}}{n}, \quad n \rightarrow \infty,
$$

where $O(1)$ is a quantity uniformly bounded with respect to $n, q$.

Here, we extend the result indicated above to the case where $q \in\left(0 ; q_{0}\right]$, $q_{0}=\sqrt{2+\sqrt{5}-2 \sqrt{2+\sqrt{5}}} \approx 0,346$.

\section{Result}

Our main result is in the following theorem.

Theorem 1 Suppose that $q \in\left(0 ; q_{0}\right]$. Then the following relation holds as $n \rightarrow \infty$

$$
\mathcal{E}\left(C_{0, \infty}^{q}, \sigma_{n}\right)=\frac{4 q}{\pi n\left(1+q^{2}\right)}+O(1) \frac{q^{n}}{n},
$$

where $O(1)$ is a quantity uniformly bounded with respect to $n, q$.

Proof.

The statement of theorem is proved using the procedure proposed in [13]. Let

$$
\delta_{n}(f ; x)=f(x)-\sigma_{n}(f ; x)=f(x)-\frac{1}{n} \sum_{k=0}^{n-1} S_{k}(f ; x)=\frac{1}{n} \sum_{k=0}^{n-1} \rho_{k}(f ; x),
$$

where

$$
\rho_{k}(f ; x)=f(x)-S_{k}(f ; x) .
$$

For $f \in C_{0, \infty}^{q}$ quantity $\rho_{m}(f ; x)$ may be represented as follows

$$
\begin{gathered}
\rho_{m}(f ; x)=\frac{1}{\pi} \int_{-\pi}^{\pi} f_{\beta}^{q}(x+t) \sum_{k=m+1}^{\infty} q^{k} \cos k t d t \\
=\frac{1}{\pi} \int_{-\pi}^{\pi} f_{\beta}^{q}(x+t) \sum_{k=0}^{\infty} q^{k+m+1} \cos (k+m+1) t d t=\frac{q^{m+1}}{\pi} \int_{-\pi}^{\pi} f_{\beta}^{q}(x+t)
\end{gathered}
$$




$$
\times\left(\cos (m+1) t \sum_{k=0}^{\infty} q^{k} \cos k t-\sin (m+1) t \sum_{k=0}^{\infty} q^{k} \sin k t\right) d t .
$$

According to formulas

$$
\sum_{k=0}^{\infty} q^{k} \cos k t=\frac{1-q \cos t}{1-2 q \cos t+q^{2}}, \quad \sum_{k=0}^{\infty} q^{k} \sin k t=\frac{q \sin t}{1-2 q \cos t+q^{2}}
$$

we obtain

$$
\begin{aligned}
\rho_{m}(f ; x)= & \frac{q^{m+1}}{\pi} \int_{-\pi}^{\pi} f_{\beta}^{q}(x+t)\left\{\frac{1-q \cos t}{1-2 q \cos t+q^{2}} \cos (m+1) t\right. \\
& \left.-\frac{q \sin t}{1-2 q \cos t+q^{2}} \sin (m+1) t\right\} d t .
\end{aligned}
$$

Comparing (2) and (3), we obtain

$$
\delta_{n}(f ; x)=\frac{1}{\pi n} \int_{-\pi}^{\pi} \frac{f_{\beta}^{q}(x+t)}{1-2 q \cos t+q^{2}} \sum_{m=1}^{n} q^{m}[\cos m t-q \cos (m-1) t] d t .
$$

We have

$$
\begin{gathered}
\sum_{k=1}^{n} q^{k}(\cos k t-q \cos (k-1) t)=\sum_{k=1}^{n} q^{k}\left(\frac{e^{i k t}+e^{-i k t}}{2}-q \frac{e^{i(k-1) t}+e^{-i(k-1) t}}{2}\right) \\
=\frac{1}{2} \sum_{k=1}^{n}\left\{\left[\left(q e^{i t}\right)^{k}+\left(q e^{-i t}\right)^{k}\right]-q^{2}\left[\left(q e^{i t}\right)^{k-1}+\left(q e^{-i t}\right)^{k-1}\right]\right\} \\
=\frac{1}{1-2 q \cos t+q^{2}}\left[\left(q+q^{3}\right) \cos t-2 q^{2}-q^{n+1}\left(\cos (n+1) t-2 q \cos n t+q^{2} \cos (n-1) t\right)\right] .
\end{gathered}
$$

Taking into account the formula (4), the following integral representation holds as $n \rightarrow \infty$

$$
\delta_{n}(f ; x)=\frac{q}{\pi n} \int_{-\pi}^{\pi} \frac{f_{\beta}^{q}(x+t)\left[\left(1+q^{2}\right) \cos t-2 q\right]}{\left(1-2 q \cos t+q^{2}\right)^{2}} d t+O(1) \frac{q^{n}}{n},
$$

where $O(1)$ is a quantity uniformly bounded with respect to $n, q$.

The function

$$
\Gamma(t)=\frac{\left(1+q^{2}\right) \cos t-2 q}{\left(1-2 q \cos t+q^{2}\right)^{2}}
$$

for $q \in(0 ; 2-\sqrt{3}$ monotonous on interval $(0 ; \pi)$. Using the relation (5), we conclude that for function $f_{\beta}^{q}(t) \in S_{M}^{0}$,

$$
S_{M}^{0}=\left\{f \in L \vdots \quad \int_{-\pi}^{\pi} f(t) d t=0, \quad \operatorname{ess} \sup |f(t)| \leq 1, \quad t \in[-\pi ; \pi]\right\}
$$


the following representation

$$
\delta_{n}(f ; x)=\frac{q}{\pi n} \int_{-\pi}^{\pi} f_{\beta}^{q}(x+t)\left(\frac{\left(1+q^{2}\right) \cos t-2 q}{\left(1-2 q \cos t+q^{2}\right)^{2}}+\frac{2 q}{\left(1+q^{2}\right)^{2}}\right) d t+O(1) \frac{q^{n}}{n}
$$

is true.

For $q \in(0 ; 2-\sqrt{3}]$ we have $\varphi(t)=\operatorname{sign}[\Gamma(t)-\Gamma(\pi / 2)] \in S_{M}^{0}$. Taking into account that $\left(f_{0}(x)\right)_{\beta}^{q}=\varphi(x)$, we obtain

$$
\begin{gathered}
\mathcal{E}\left(C_{0, \infty}^{q}, \sigma_{n}\right)=\frac{q}{\pi n} \int_{-\pi}^{\pi} \varphi(t)\left(\frac{\left(1+q^{2}\right) \cos t-2 q}{\left(1-2 q \cos t+q^{2}\right)^{2}}+\frac{2 q}{\left(1+q^{2}\right)^{2}}\right) d t+O(1) \frac{q^{n}}{n} \\
=\frac{2 q}{\pi n} \int_{0}^{\pi}\left|\frac{\left(1+q^{2}\right) \cos t-2 q}{\left(1-2 q \cos t+q^{2}\right)^{2}}+\frac{2 q}{\left(1+q^{2}\right)^{2}}\right| d t+O(1) \frac{q^{n}}{n} .
\end{gathered}
$$

It is clear that, for $q$ such that $\Gamma(t)-\Gamma(\pi / 2)>0, t \in(0 ; \pi / 2)$ and $\Gamma(t)-$ $\Gamma(\pi / 2)<0, t \in(\pi / 2 ; \pi)$ the formula $(6)$ is true.

We investigate the function $\Gamma(t)$. We have

$$
\Gamma^{\prime}(t)=\frac{\left(6 q^{2}-q^{4}-1-2 q\left(1+q^{2}\right) \cos t\right) \sin t}{\left(1-2 q \cos t+q^{2}\right)^{3}} .
$$

Performing elementary transformations, for $q \in(0 ; 2-\sqrt{3}]$ we get

$$
\Gamma^{\prime}(t) \neq 0, t \in(0 ; \pi) .
$$

It was also shown in [13]. Further, $\Gamma^{\prime}(t)=0$ for $q \in(2-\sqrt{3} ; 1)$ such that satisfy the condition

$$
\cos t=\frac{6 q^{2}-q^{4}-1}{2 q\left(1+q^{2}\right)} .
$$

For $t \in(\pi / 2 ; \pi)$ this relation is true as

$$
-1 \leq \frac{6 q^{2}-q^{4}-1}{2 q\left(1+q^{2}\right)} \leq 0 .
$$

Making calculations, we obtain $q \in(2-\sqrt{3} ; \sqrt{3-2 \sqrt{2}})$.

Consider the condition $\Gamma(q, \pi)-\Gamma(q, \pi / 2) \leq 0$. The last inequality yields for

$$
q^{4}-2 q^{3}-2 q^{2}-2 q+1 \geq 0 .
$$

Making calculations, we have $q \in\left(0 ; q_{0}\right]$.

In view of the properties of monotonicity of function $\Gamma(t)$, for $q \in\left(0 ; q_{0}\right]$ we have $\varphi(t)=\operatorname{sign}[\Gamma(t)-\Gamma(\pi / 2)] \in S_{M}^{0}$. Therefore, for function $\left(f_{0}(x)\right)_{\beta}^{q}=\varphi(x)$ the relation (6) is true. 
It is clear that

$$
\begin{gathered}
\int_{0}^{\pi}\left|\frac{\left(1+q^{2}\right) \cos t-2 q}{\left(1-2 q \cos t+q^{2}\right)^{2}}+\frac{2 q}{\left(1+q^{2}\right)^{2}}\right| d t \\
=\int_{0}^{\pi / 2} \frac{\left(1+q^{2}\right) \cos t-2 q}{\left(1-2 q \cos t+q^{2}\right)^{2}} d t-\int_{\pi / 2}^{\pi} \frac{\left(1+q^{2}\right) \cos t-2 q}{\left(1-2 q \cos t+q^{2}\right)^{2}} d t .
\end{gathered}
$$

Making calculations, we obtain

$$
\begin{gathered}
\int \frac{\cos t}{\left(1-2 q \cos t+q^{2}\right)^{2}} d t=\frac{\left(1+q^{2}\right) \sin t}{\left(1-q^{2}\right)^{2}\left(1-2 q \cos t+q^{2}\right)} \\
+\frac{2 q}{\left(1-q^{2}\right)^{2}} \int \frac{d t}{1-2 q \cos t+q^{2}}, \\
\int \frac{d t}{\left(1-2 q \cos t+q^{2}\right)^{2}}=\frac{2 q \sin t}{\left(1-q^{2}\right)^{2}\left(1-2 q \cos t+q^{2}\right)} \\
+\frac{1+q^{2}}{\left(1-q^{2}\right)^{2}} \int \frac{d t}{1-2 q \cos t+q^{2}} .
\end{gathered}
$$

Making elementary transformations, we obtain

$$
\begin{gathered}
\int \frac{\left(1+q^{2}\right) \cos t-2 q}{\left(1-2 q \cos t+q^{2}\right)^{2}} d t=\frac{\sin t}{1-2 q \cos t+q^{2}} \\
\int_{0}^{\pi / 2} \frac{\left(1+q^{2}\right) \cos t-2 q}{\left(1-2 q \cos t+q^{2}\right)^{2}} d t-\int_{\pi / 2}^{\pi} \frac{\left(1+q^{2}\right) \cos t-2 q}{\left(1-2 q \cos t+q^{2}\right)^{2}} d t=\frac{2}{1+q^{2}} .
\end{gathered}
$$

Combining relations (6), (7), we arrive at the statement of the theorem. The theorem is proved.

The formula (1) provides the solving of the Kolmogorov-Nikolsky problem (see, e.g., $[14,15])$ when performing the theorems conditions without any additional conditions.

\section{REFERENCES}

1. A.I. Stepanec. Solution of the Kolmogorov-Nikol'skij problem for the Poisson integrals of continuous functions. Mat. Sb., 2001. - 192(1). - P. 113-138 (in Russian).

2. S.M. Nikolskiy. Approximation of the functions by trigonometric polynomials in the mean. Izv. Acad. Nauk. SSSR, Ser. Mat., 1946. -10(3). - P. 207-256 (in Russian). 
3. S.B. Stechkin. Estimation of the remainder of Fourier series for the differentiable functions. Tr. Mat. Inst. Acad. Nauk SSSR. - 1980. - 145. - P. 126-151 (in Russian).

4. V.I. Rukasov, S.O. Chaichenko. Approximation of the classes of analytical functions by de la Vallee-Poussin sums. Ukr. Math. J. - 2002. - 54. P. 2006-2024.

5. A.S. Serdyuk. Approximation of Poisson integrals by de la Vallee Poussin sums. Ukr. Math. J. - 2004. - 56. - P. 122-134.

6. V.V. Savchuk, M.V. Savchuk, S.O. Chaichenko. Approximation of analytic functions by de la Vallee Poussin sums. Mat. Stud. - 2010. - 34(2). P. 207-219 (in Ukrainian).

7. O.O. Rovenska, O.O. Novikov. P. Approximation of Poisson integrals by repeated de la Vallee Poussin sums. Nonl. Oscil. — 2010. - 13. - P. 108-111.

8. V.E. Velichko, O.A. Novikov, O.G. Rovenskaya. V.I. Rukasov. Approximation of analytic functions by repeated de la Vallee Poussin sums. Tr. Inst. Prikl. Mat. Mekh. - 2011. - 22. - P. 33-42 (in Rusian).

9. O.A. Novikov, O.G. Rovenska. Approximation of classes of Poisson integrals by Fejer sums. Computer Research and Modeling. - 2015. - 7 (4). P. 813-819 (in Russian).

10. O.O. Novikov, O.G. Rovenska, Yu.V. Kozachenko. Approximation of Poussin integrals by Fejer sums. Modern problems of probability theory and mathematical analysis. Scientific conference, Vorohta, 24-27 February, 2016, P. 110 (in Ukrainian).

11. O.G. Rovenska, O.O. Novikov. Approximation of analytic periodic functions by linear means of Fourier series. Cheb. Sb. - 2016. - 17 (2). - P. 170-183 (in Russian).

12. O.Novikov, O. Rovenska. Approximation of Classes of Poisson Integrals by Repeated Fejer Sums. Lobachevskii Journal of Mathematics. - 2017. - 38. P. 502-509.

13. O.O. Novikov, O.G. Rovenska. Approximation of periodic analytic functions by Fejer sums. Mat. Stud. - 2017. - 47. - P. 196-201.

14. A.I. Stepanec, Classification and Approximation of Periodic Functions. 1987. Naukova Dumka, Kiev, 268 p. (in Russian).

15. A.I. Stepanec, Classification and Approximation of Periodic Functions. 1995. Dordrecht, Kluwer, 393 p. 
Новіков О.О., Ровенська О.Г., Козаченко Ю.А. Наближення класів інтегралів Пуассона сумами Фейєра. У роботі вивчаються питання наближення періодичних диференційовних функцій високої гладкості лінійними середніми рядів Фур'є. Одна з класифікацій періодичних функцій - класифікація, що заснована на понятті $(\psi ; \beta)$-диференціювання. Ця класифікація дозволяе ранжувати великий спектр періодичних функцій - від функцій, ряди Фур'є яких можуть розбігатися до цілих і аналітичних. За належного вибору параметрів, що визначають клас, класи $(\psi ; \beta)$-диференційовних функцій можуть збігатися з класами згорток з інтегрованими ядрами.

Мета роботи - представити нові факти, що стосуються апроксимаційних властивостей сум Фейєра на класах функцій, які визначаються мультиплікаторами, у випадку, коли ці послідовності прямують до нуля зі швидкістю геометричної прогресії. За цієї умови, вищезгадані класи складаються з функцій, які можна регулярно подовжити у відповідну смугу комплексної площини.

Питання, що стосуються наближення класів інтегралів Пуассона різними лінійними методами вивчалися в роботах С. Нікольського, С. Стєчкіна, В. Рукасова, С. Чайченка, А. Сердюка та інших авторів. 3 результатів цих робіт відомо, що на класах інтегралів Пуассона суми Фур'є забезпечують порядок наближення, який збігається з порядком найкращого наближення цих класів тригонометричними многочленами порядку не вищого за n. Проте дослідження апроксимаційних властивостей інших методів наближення може бути корисним в обчислювальній математиці, математичному моделюванні тощо.

В роботі розширено проміжок параметру, що визначає клас функцій, для яких є справедливою знайдена нами до цього асимптотична формула для верхніх граней відхилень сум Фейєра на класах інтегралів Пуассона. Отримана формула є асимптотично точною за будь-якого значення параметрів, що входять до неї.

Ключові слова: асимптотична рівність; інтеграли Пуассона; суми Фейєра

Article history: Received: 9 January 2018; Final form: 21 January 2018; Accepted: 30 January 2018. 